\title{
ASPECTOS PETROGRÁFICOS E VULCANOLÓGICOS DA PROVÍNCIA ALCALINA-CARBONATÍTICA DE SANTO ANTÔNIO DA BARRA, SUDOESTE DE GOIÁS
}

\author{
JOSÉ C. GASPAR* e JOSÉ CARUSO MORESCO DANNI**
}

\begin{abstract}
The volcanic province of Santo Antônio da Barra located in the southwestern portion of Goiás is of Cretaceous age ( $\pm 85,8 \mathrm{~m} . \mathrm{y}$.), and comprises a heterogeneous sequence of analcitic rocks (pyroclastic and flows), locally capped by flows, tuffs, and agglomerates of silicocarbonatitic composition. Rests of volcanic structures and a great number of pypes and vents formed by fourchites and melamonchiquites are found tectonically controlled by NW-trending faults. They are regarded as differentiated hypoabyssal products of continental volcanism of nefelinitic type.

It is reported in Brazil for the first time the occurrence of carbonatitic volcanoclastics related to the terminal stage of analcimitic volcanism.
\end{abstract}

INTRODUÇÃO A província vulcânica alcalina de Santo Antônio da Barra, de idade 85,8 m.a. (Hasui et $a l ., 1971)$, constitui a porção mais meridional de um conjunto de manifestaçðes magmáticas instaladas durante o Cretácio Superior no sudoeste de Goiás (Fig. 1).

Bez e Guimarães (1971) apontaram para as rochas vulcânicas da região uma filiação subsaturada potássica enquanto Gaspar (1977) demonstrou serem elas de caráter nefelinítico.

Enquanto nas regioes periféricas da Bacia do Paraná este magmatismo se exprime por uńa sucessão de complexos diferenciados de tipo central (peridotitos, piroxenitos, gabros alcalinos, nefelina sienitos, etc.), na região de Santo Antônio da Barra encontram-se preservados os produtos superficiais (lavas, brechas, tufos, etc.) desta época de atividade magmática.

Com efeito, sobre o assoalho irregular dos basaltos (Formação Serra Geral) e localmente sobre arenitos da Formação Botucatu, depositou-se um geterogêneo pacote, com cerca de $200 \mathrm{~m}$ de espessura, de lavas e piroclásticas analcimíticas e carbonáticas, ao mesmo tempo em que se instalou um grande número de condutos. Localmente, reconhecem-se restos de edifícios vulcânicos.

Essas unidades encontram-se recobertas por arenitos do Grupo Bauru, em situação análoga à do Fácies Patos (Ladeira et al., 1971), em Minas Gerais.

A extensão total da província não é bem conhecida mas é certo que se estende principalmente para norte, talvez por mais de uma dezena de quilômetros. Para oeste, sua continuidade foi constatada até $15 \mathrm{~km}$ de Santo Antônio da Barra, na estrada para Rio Verde.

A província em questão alinha-se com outras manifestaçðes magmáticas de caráter ultrabásico-alcalino, segundo uma direção aproximada $\mathrm{N} 40 \mathrm{~W}$, incluindo as ocorrências da Fazenda Água Emendada, Paraúna; Amorinópolis e Iporá, definindo assim uma zona de fraturamento profundo (Danni, 1974). Pena (1974) identificou segundo esta direção um eixo de arqueamento regional.

São também correlacionáveis a esta província, tanto no tempo quanto em filiação, os corpos intrusivos com carbonatitos de toda a borda setentrional e oriental da Bacia do Paraná, bem como as lavas do Fácies Patos do Grupo Mata da Corda, na Bacia Sanfranciscana em Minas Gerais.

ESTRATIGRAFIA A seqüência litológica observada na área encontra-se representada na Fig. 2 e compreende as seguinte unidades:

\section{A - GRUPO SÃO BENTO}

Os basaltos da Formação Serra Geral constituem localmente soleiras dos principais rios da região e são representados por derrames de basaltos fortemente oxidados e alterados (clorofeíta) por efeito de soluções deutéricas.

Poucos e isolados afloramentos de arenitos róseos da Formação Botucatu são registrados na região, não permitindo estabelecer seu relacionamento estratigráfico com os basaltos.

\section{B - AS UNIDADES VULCANICAS}

$\mathrm{Na}$ região, encontram-se representados extensos depósitos de derrames de lavas intercaladas a depósitos piroclásticos cortados por condutos vulcânicos e diques.

1. Entre as rochas extrusivas podem ser individualizadas três unidades:

a. Analcimitos e olivina analcimitos com intercalaçoes de brechas analcimíticas.

$b$. Brechas analcimíticas com analcimitos e olivina analcimitos intercalados.

c. Lavas e piroclásticas carbonatíticas.

As unidades $a$ e $b$ diferenciam-se só pela abundância relativa dos fácies piroclásticos. Na unidade inferior, 


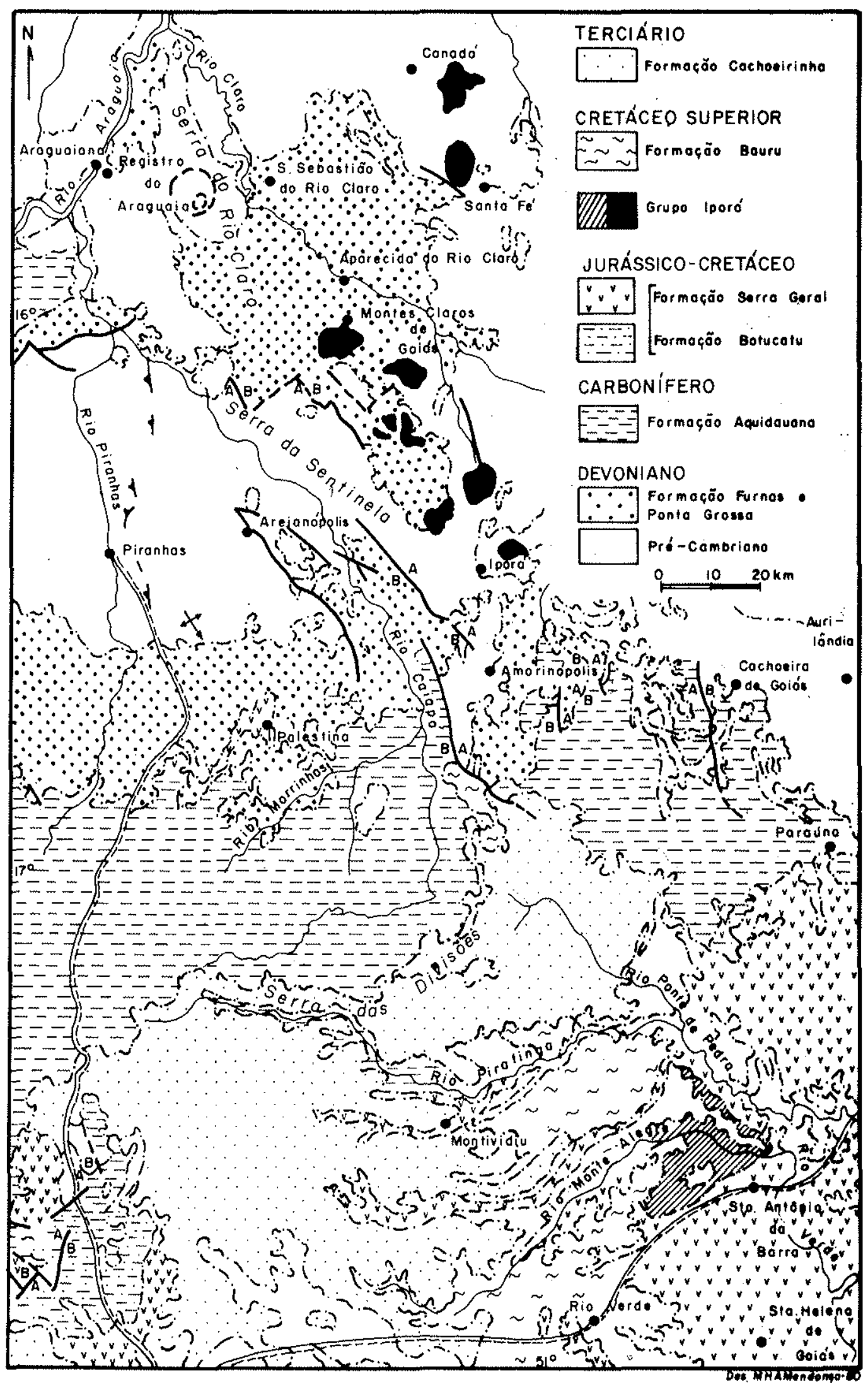

Figura 1 - Província alcalina do sudoeste de Goiás 


\begin{tabular}{|c|c|c|c|c|}
\hline 密 & & & & Silexitos e brechas'silicificadas formados ao longo das falhas \\
\hline \multirow{7}{*}{ 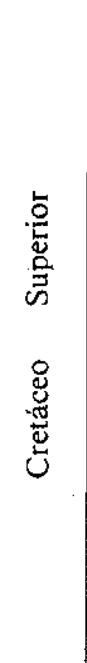 } & \multirow[t]{2}{*}{ Grupo } & Bauru & & $\begin{array}{l}\text { Arenitos esverdeados e avermílhados muito silicificados, normalmente médios, } \\
\text { com conglomerado basal lenticular }\end{array}$ \\
\hline & & $\begin{array}{l}\text { Fácies Ponte } \\
\text { Alta }\end{array}$ & & Calcário conglomerático com seixos de calcário oolítico e quartzo \\
\hline & Formação & Verdinho & & $\begin{array}{l}\text { Conglomerado vulcânico com granulometria variável, seixos bem arredondados } \\
\text { e matriz arenosa tufácea, com cimento de calcita. Intercalaçôes de arenito } \\
\text { tufáceo }\end{array}$ \\
\hline & $\begin{array}{l}\text { Condutos } \\
\text { e diques }\end{array}$ & vulcânicos & & Condutos vulcânicos e diques de fourchitos, melamonchiquitos e raros fonólitos \\
\hline & \multirow{3}{*}{\multicolumn{2}{|c|}{ Derrames }} & A & Lavas e piroclásticas carbonatíticas \\
\hline & & & B & $\begin{array}{l}\text { Brechas analcimíticas com derrames de analcimitos e olivina analcimitos interca- } \\
\text { lados }\end{array}$ \\
\hline & & & $\mathrm{C}$ & Derrames de analcimitos com intercalaçðes de brechas analcimíticas \\
\hline \multirow{2}{*}{ 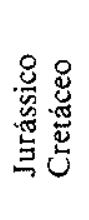 } & Grupo & $\begin{array}{l}\text { Formação } \\
\text { Serra Geral }\end{array}$ & & $\begin{array}{l}\text { Basalto toleítico com textura hialofítica, oxidado e apresentando alterações } \\
\text { deutéricas }\end{array}$ \\
\hline & $\begin{array}{l}\text { São } \\
\text { Bento }\end{array}$ & $\begin{array}{l}\text { Formação } \\
\text { Botucatu }\end{array}$ & & $\begin{array}{l}\text { Arenito amarelado, normalmente médio, bem arredondado com estratificação } \\
\text { cruzada }\end{array}$ \\
\hline
\end{tabular}

Figura 2 - Coluna estratigráfica geral

predominam depósitos lávicos enquanto, na segunda, há maior quantidade de brechas e, localmente, lapillis e tufos. A unidade superior é de ocorrência restrita e singulariza-se pela presença de lavas e brechas localmente muito ricas em carbonatos. Sua espessura aflorante situa-se entre 10 e $15 \mathrm{~m}$.

\section{Condutos Vulcânicos}

Cerca de oitenta condutos vulcânicos são identificáveis na área estudada (Figs. 3 e 4), além de alguns diques. Os condutos formam elevaçðes com seçðes circulares e com diâmetros de alguns metros a mais de $300 \mathrm{~m}$. Petrograficamente, são compostos por melamonchiquitos, fourchitos e ocasionalmente por fonólitos, e são, portanto, à exceção dos fonólitos, de mesma natureza que as lavas circundantes.

Dado seu caráter nitidamente intrusivo, certamente representam raízes de edifícios vulcânicos desmantelados pela erosão no fím do Cretáceo como bem demonstra a existência dos conglomerados vulcânicos epiclásticos superpostos às unidades vulcânicas superficiais (derrames e brechas piroclásticas).

\section{C - FORMAÇÃO VERDINHO}

Acima das brechas e lavas analcimíticas existe um conglomerado vulcânico epiclástico formado por seixos e matacões de até $30 \mathrm{~cm}$, derivados do retrabalhamento das rochas vulcânicas imediatamente sotopostas. Em ordem de abundância, reconhecem-se seixos de fonolitos (cerca de $70 \%$ dos seixos), traquitos, analcimitos, olivina analcimitos, fourchitos a biotita, malignitos e fragmentos de cristais de titanaugita, opacos, sanidina, etc. Sua matriz é formada por uma areia lítica (correspondendo a um arenito tufáceo na classificação de Fisher, 1966) cimentada por calcita.

A espessura média no local-tipo (morro da antena da Embratel) é da ordem de $40 \mathrm{~m}$, sendo sobreposto pelo conglomerado basal silicificado do Grupo Bauru. Na escarpa setentrional do Ribeirão Boa Vista, torna-se mais delgado, parecendo mesmo se acunhar e faltar no extremo oeste da área.

Em razão de sua posição estratigráfica específica, sob os conglomerados basais do Grupo Bauru, e em vista de sua natureza sedimentar (epiclastos vulcânicos), propomos a denominação Formação Verdinho para estes conglomerados em substituição ao conceito de fácies proposto por Hasui et al. (1971), posto que seu contato inferior com as lavas é tipicamente erosional.

Sua correlação com a Fácies Uberaba (Hasui, 1968) é clara, mas é mais estreita ainda com a Fácies Capacete do Grupo Mata da Corda (Ladeira e Brito, 1968).

\section{D - GRUPO BAURU}

Este grupo ocorre em camadas, sub-horizontais que recobrem os morros testemunhos e chapadas. Inicia-se por um conglomerado basal lenticular, bastante silicificado, que não ultrapassa $10 \mathrm{~m}$ de espessura.Possui seixos de quartzo e de quartzitos, e matriz quartzosa grosseira e média. Face à diminuição da quantidade de seus seixos, transiciona verticalmente para arenitos. Estes têm coloração esverdeada, amarela ou avermelhada, granulação 


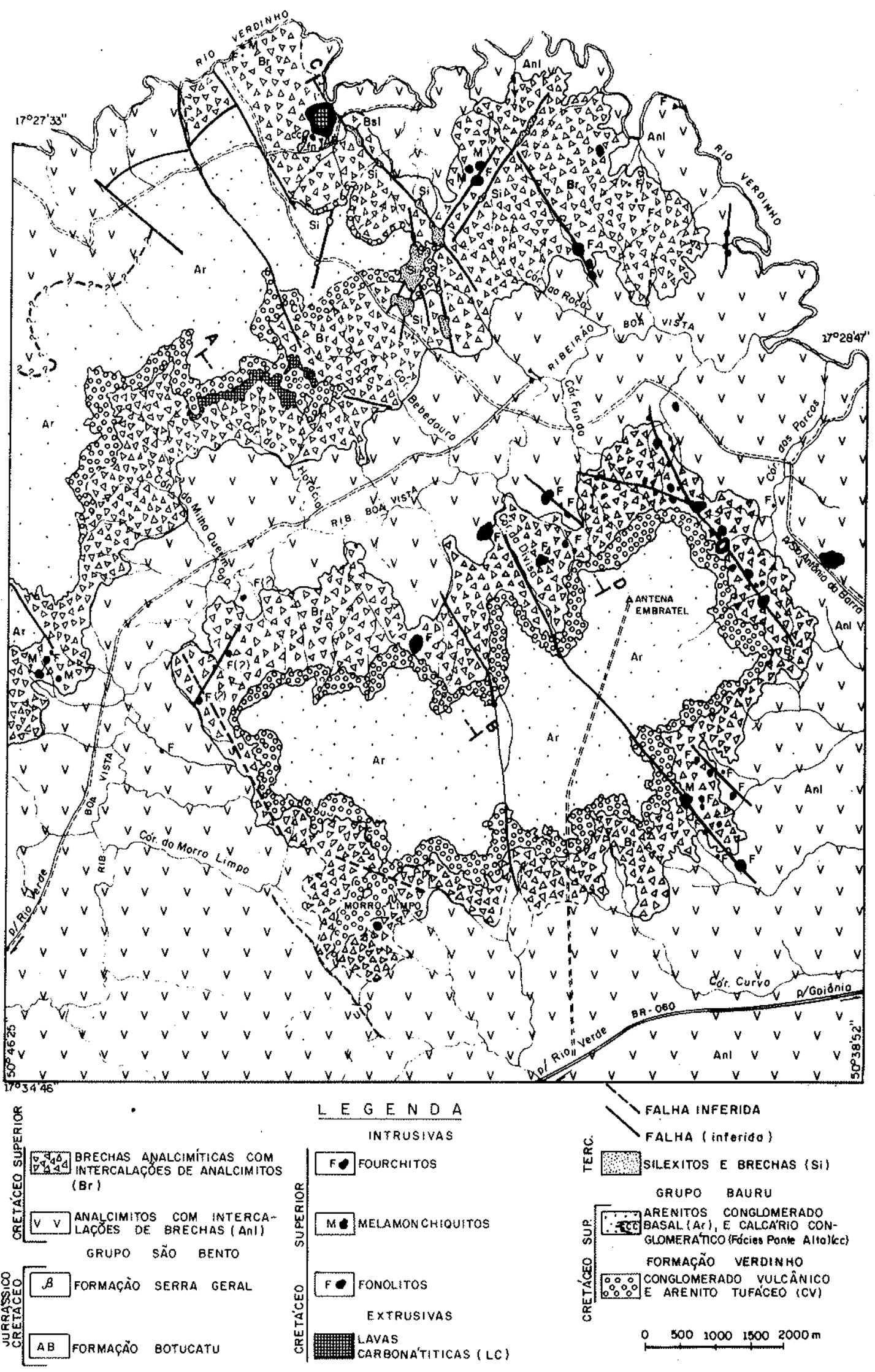

Figura 3 - Mapa geológico 

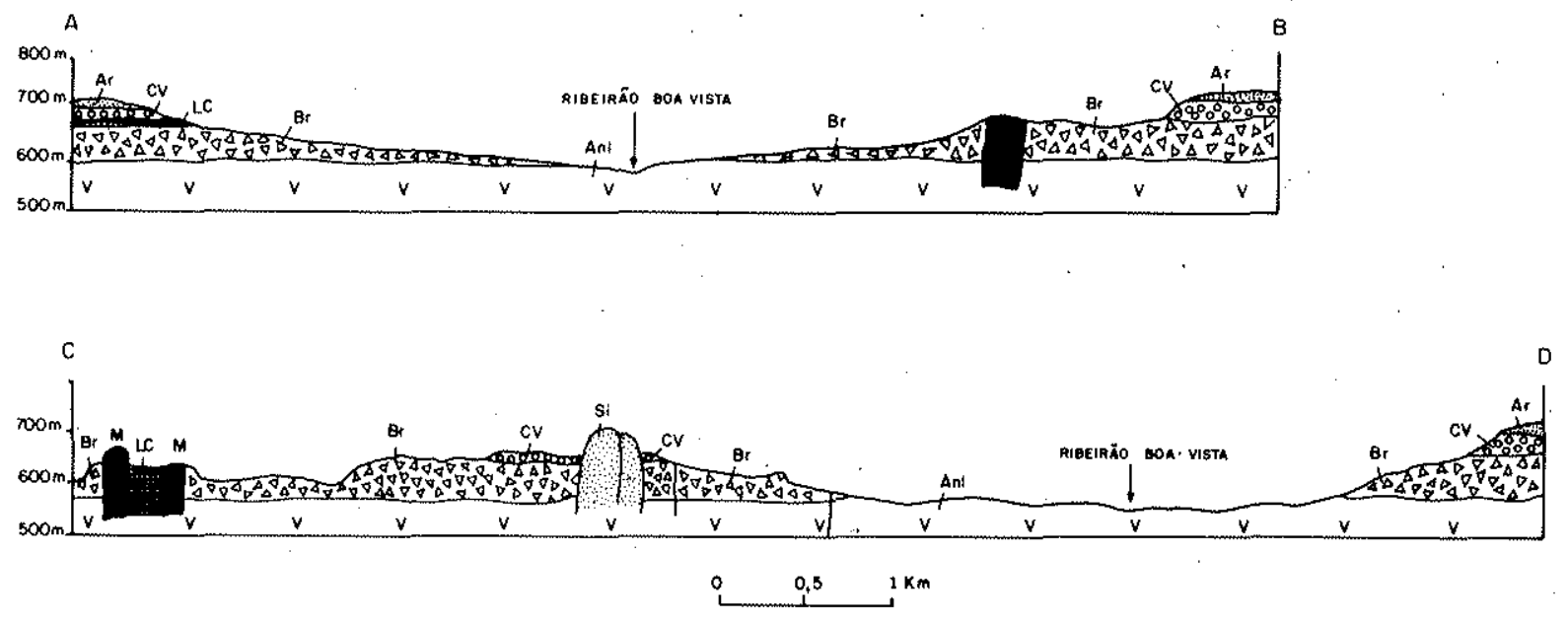

SÍMBOLOS CONFORME INOICADO NO MAPA GEOLGGICO (FIG. J)

Figura $4-$ Seções geológicas

média, e apresentam-se intensamente silicificados. Atingem, junto com o conglomerado, cerca de $100 \mathrm{~m}$ de espessura.

A Fácies Ponte Alta foi encontrada capeando um pequeno morro testemunho no norte da área, onde apresenta uma espessura de aproximadamente $5 \mathrm{~m}$. Trata-se de um calcário conglomerático branco, com seixos de quartzo e de calcário oolítico. Uma densa rede de vênulas de silicificação com alguma recristalização de carbonato está presente nesta litologia.

Pena (1974) considera o Grupo Baurư como anterior às vulcânicas alcalinas da região. Esta não é com certeza a posição relativa da referida unidade dado que os arenitos recobrem nitidamente aquelas rochas.

\section{$\mathrm{E}-\mathrm{SILEXITOS}$}

Os silexitos formam estreitas e alongadas cristas condicionadas às linhas tectônicas de direções NW. Onde a silicificação não foi completa, existe uma brecha silicificada composta de arenitos do Grupo Bauru. A época de formação dessas massas silexíticas é ainda de difícil diagnóstico, podendo-se no entanto situá-la entre a deposição do Grupo Bauru e o estabelecimento da superfície de laterização do fím do Terciário.

O VULCANISMO O vulcanismo de Santo Antônio da Barra foi controlado por falhas e fraturas de direçōes NW. Este controle torna-se evidente quando se observa o alinhamento sistemático dos inúmeros condutos vulcânicos. Essas direçōes NW foram posteriormente reativadas, dando origem às cristas de silexitos acima descritas.

O início do fenômeno vulcânico certamente está correlacionado ao estabelecimento de grandes falhas regio- nais profundas que delimitam o lineamento tectonomagmático Santo Antônio da Barra-Iporá, de direção geral N40-50W. A origem dessas falhas é discutivel, sendo a idéia mais plausível a que as considera como pònolongamento, no continente das direções das falhas transformantes identificadas no Oceano Atlântico (Danni, 1974; e Sadowski, 1976). Hasui et al. (1976) acreditam que os atuais traços tectônicos representam antigas direções de falhas reativadas durante o'Cretáceo.

Pena (1974) ad'nite a existência de um amplo eixo de arqueamento de direção NW que teria afetado toda a região SW de Goiás e que condicionaria a localização do magmatismo alcalino da região.

A ascensão do magma foi relativamente rápida a se julgar pela natureza explosiva das rochas bem como pela forte zonação em Canos fenocristais de olivina (Gaspar, 1977). Apesar disso, devem ter ocorrido períodos intermitentes de baixa velocidade que permitiram a precipitação de fenocristais (olivina, titanaugita e analcita). Este aspecto é também evidenciado pela presença de nódulos de peridotipos cumulados encontrados na província.

A extrusão do magma deve ter ocorrido através dos inúmeros condutos que atualmente se alinham ao longo das direções tectônicas, formando cadeias de cones vulcânicos. A intermitência e a explosividade do vulcanismo podem ser inferidas pelas intercalações de brechas e de derrames de lavas. Cada manifestação, seja em forma de lava ou de brecha, parece ter sido de curta duração; fato que é evidenciado pela pequena espessura de cada nível. Cada pulsação, de modo geral, deve ter-se caracterizado por três fases:

$a$. Derrames de lavas

b. Cessação dos derrames e consolidação do material no conduto 
c. Explosão do material consolidado no conduto, originada pela acumulação de gases em câmaras subvulcânicas (Foto 1). A ausência de bombas é uma evidência de que essas fases explosivas se processaram em condutos então consolidados.

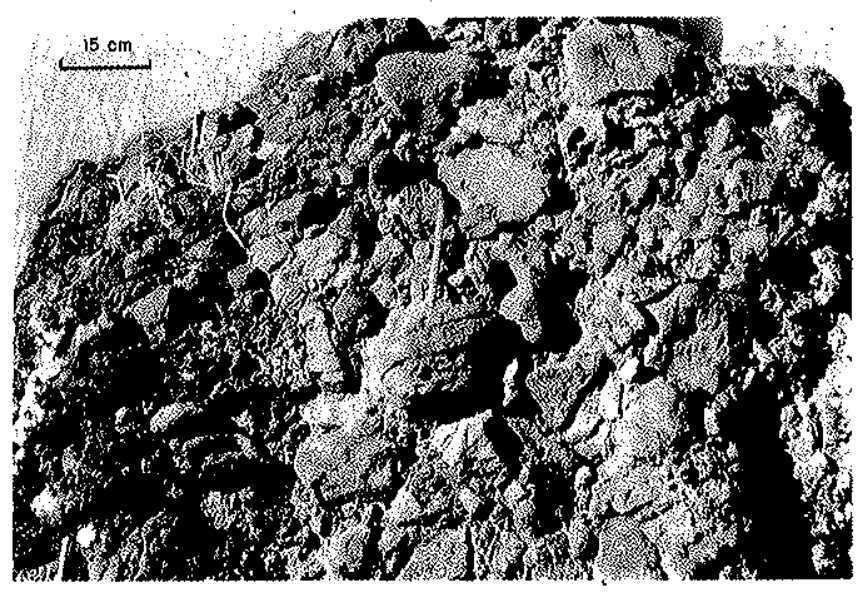

Foto 1 - Brechas de explosão que ocorrem nos condutos vulcânicos. A brecha, com fragmentos maiores (centro da foto), é intrusiva em outra de fragmento menores (lado esquerdo da foto). O contato é subvertical

A repetição deste processo, centrado nos inúmeros condutos existentes, explica as intercalações de depósitos piroclásticos e de lavas. Gaspar (1977) caracteriza e descreve os vários tipos de brechas resultantes deste mecanismo. Os produtos do vulcanismo somam mais de $200 \mathrm{~m}$ de espessura de rochas què, compreendem brechas e lavas de analcimitos, olivina analcimitos e fourchitos, melamonchiquitos, fonolitos e as lavas e brechas carbonatíticas. Diques de fourchitos e melamonchiquitos cortam ocasionalmente a sequência extrusiva em níveis variados.

\section{A. TIPOS PETROGRÁFICOS}

1 - ANALCIMITOS E OLIVINA ANALCIMI-

TOS Estes são os tipos petrográficos predominantes já que constituem as lavas e as brechas. Formam juntos com seus correspondentes hipoabissais (fourchitos e melamonchiquitos) mais de $90 \%$ das rochas da província.

São rochas porfiríticas com matriz afanítica e normalmente ricas em amígdalas. Têm coloração que varia de cinza-escuro a tons de marrom-avermelhado, dependendo do grau de alteração, o que facilita a distinção entre sucessivos derrames.

A estrutura de fluxo é rara e, quando ocorre, é resultante da orientação dos cristais de clinopiroxênio.

Megascopicamente, caracterizam-se por apresentar grande quantidade de fenocristais e de amígdalas preenchidas por zeolitas e/ou calcita com dimensões de 0,1 a $0,5 \mathrm{~cm}$ (Foto 2 ).

Os fenocristais são de três tipos: titanaugita, olivina (normalmente alterada) e analcima. Em uma mesma rocha podem ocorrer um, dois ou três tipos, exceto a combinação olivina-analcima (sem titanaugita). Enquanto a titanaugita e a analcima integram a matriz dessas ro-

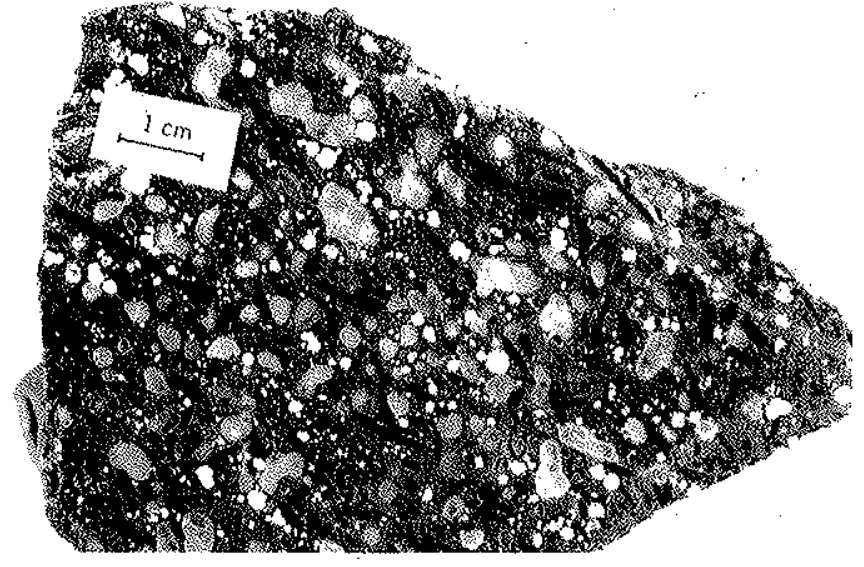

Foto 2 - Aspecto típico dos analcimitos: fenocristais de titanaugita e analcima, e amígdalas com calcitas e zeólitas

chas, a olivina, quando presente, só ocorre em fenocristais, diferenciando os tipos petrográficos acima enunciados.

Microscopicamente, apresentam texturas porfiriticas ou glomeroporfiríticas com uma matriz formada principalmente por titanaugita, analcima e magnetita, podendo conter zeólita, perovskita, flogopita, nefelina, apatita e um anfibólio muito fino do tipo kaersutita.

Os fenocristais de titanaugita são normalmente zonados com bordas progressivamente mais ricas em Ti. Essas bordas certamente cristalizaram-se ao mesmo tempo que a matriz, uma véz que contém freqüentemente inclusões de minerais matriciais. Quando integrante da matriz, este clinopiroxênio está representado por finos prismas alongados.

Os fenocristais de olivina, quase invariavelmente, estão alterados para iddingsita, bowlingita e/ou magnetita.

A analcima, seja como fenocristal ou na matriz, tem hábito sempre arredondado, mostrando muitas vezes inclusões circulares de finos cristais de magnetita e titanaugita. Os fenocristais ocorrem em aglomerados de mais de três cristais sob a forma de rosáceas. Têm coloração entre amarelo-pálido e caramelo enquanto os cristais da matriz são incolores. Os fenocristais podem mostrar maclas complexas.

As amígdalas são preenchidas por zeolita e/ou calcita. Quando presentes em uma mesma amígdala, as zeolitas recobrem as paredes, e a calcita ocupa o centro. São também comuns veios irregulares de calcita de 1 a 2 $\mathrm{cm}$.

De acordo com Johannsen (1938), rochas com estas características são classificadas como analcima-basalto. No entanto, preferiu-se a denominação olivina analcimito (Streckeisen, 1978), mais apropriada e que evita a idéia de filiação basáltica para essas rochas.

\section{2 - FOURCHITOS E MELAMONCHIQUI-}

TOS Os fourchitos e os melamonchiquitos são, respectivamente, os correspondentes hipoabissais dos analcimitos e dos olivina analcimitos. Johannsen (1938) aplica para o correspondente hipoabissal do analcima basalto (olivina analcimito) o termo "baldito". Como o 
baldito é na realidade um monchiquito onde os máficos são mais abundantes, optou-se pela denominação melamonchiquito, que expressa bem a rocha e tem a vantagem de ser um termo mais divulgado.

São estas as rochas que constituem a quase totalidade dos condutos vulcânicos e diques da região.

De modo geral, esses correspondentes hipoabissais diferenciam-se das lavas e brechas pelo menor grau de intemperismo e pela menor abundância de amígdalas. Os fourchitos caracterizam-se ainda por ser praticamente isentos de fenocristais. Quando presentes trata-se de titaunagita.

Os fourchitos têm cor de cinza a preto enquanto os melamonchiquitos têm tons esverdeados devido à presença de olivina. A olivina ocorre nos melamonchiquitos como fenocristais (com ou sem titanaugita), sendo ausente nos fourchitos. Normalmente, possui hábito euedral ou com figuras de corrosão.

A presença de fenocristais de analcima nas rochas intrusivas é rara, tendo sido abundantemente encontrada só em dois diques de fourchitos.

A flogopita apresenta-se mais abundante nos melamonchiquitos que em qualquer outra rocha, chegando em alguns condutos a ocorrer em grandes cristais, desenvolvidos a partir das bordas dos fenocristais de olivina.

Além desses aspectos, é notável a ocorrência esporádica de nódulos cumulados de olivina (dunito) e de olivina e clinopiroxênio (weherlitos) no interior dos condutos de melamonchiquitos.

\section{3 - LAVAS E PIROCLÁSTICAS CARBONATÍTI-} CAS São rochas de cor marrom-esbranquiçada, ora com feiçôes estruturais de derrames de lavas, ora de brechas. Por essa razão, deu-se preferência a uma caracterização faciológica mais ampla, incluindo fatores, tais como composição dos fragmentos e forma de ocorrência do carbonato. Assim, podem-se identificar três fácies que, por ordem decrescente de abundância, são:

a. Brechas e lavas analcimíticas possuindo uma fração carbonática contínua sob a forma de bolsões e vênulas anastomosados (Foto 3 ).

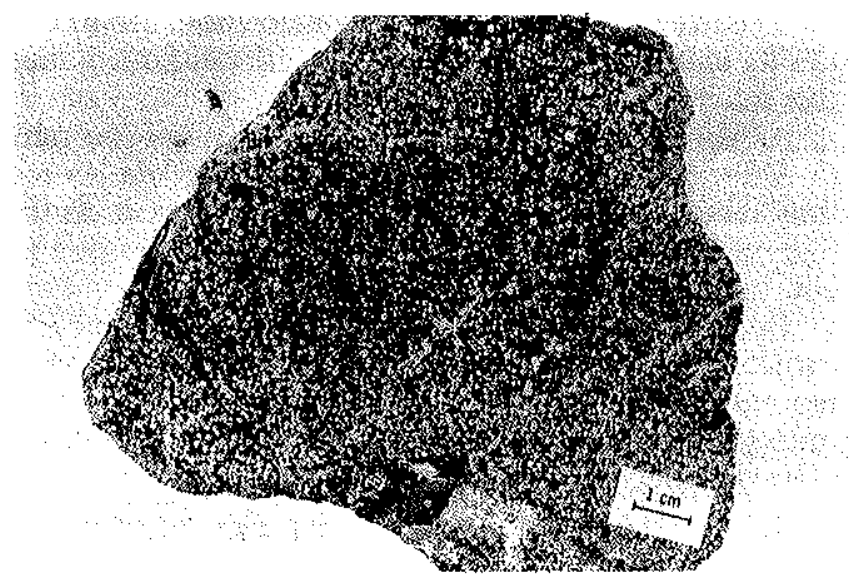

Foto 3 - Fácies esferoidal de lava silico-carbonatítica. Materializa um "aerossol" gás-líquido carbonatítico disperso numa lava analcimítica. Observa-se início de coalescência das fraçðes carbonáticas $b$. Lavas e brechas analcimíticas ricas em fenocristais de titanaugita e flogopita associada a uma fração carbonática contínua.

c. Lavas e brechas analcimíticas afaníticas que contêm uma abundante fração carbonática esferoidal (Foto 4 ).

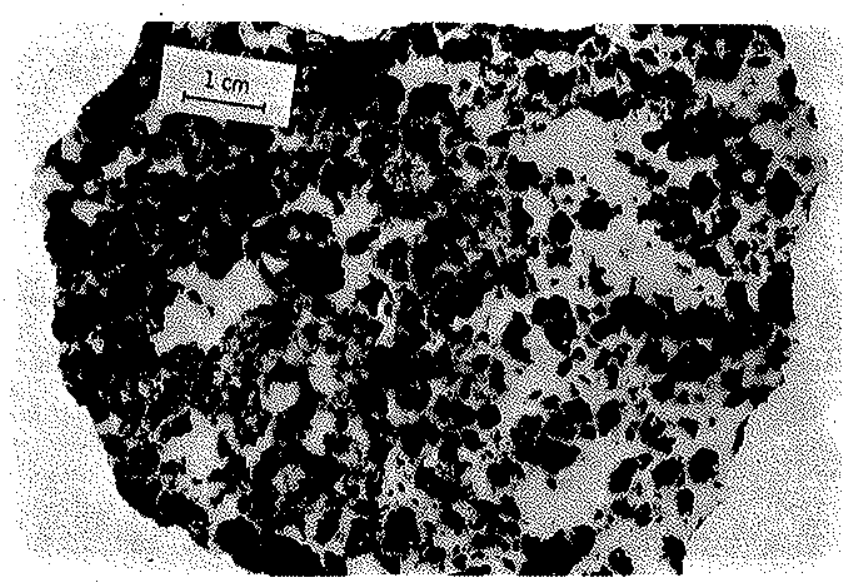

Foto 4 - Tufo-lava sílico carbonatítico com a fase carbonática contínua em razão de sua coalescência. A fração silicática é de composição analcimítica

Os dois primeiros fácies distinguem-se pela presença ou não de fenocristais e apresentam uma passagem gradacional no campo. O terceiro fácies tem ocorrência muito localizada, situando-se no topo do pacote vulcanoclástico e no núcleo de um condutò vulcânico.

$\mathrm{O}$ fácies $a$ é mais abundante apresentando-se sob a forma de brechas, lapilli ou como lavas, de difícil distinção entre si. Em determinados pontos, distinguem-se claramente caracteres piroclásticos, posto que contém fragmentos de analcimitos embalados numa matriz mais fina e estrutura estratificadas.

O carbonato cimenta as porçðes silicáticas mas pode ocorrer como diminutas esferas. Observa-se que a fração carbonática contínua originou-se pela coalescência e interligação de inúmeras esferas calcíticas produzindo porçoes amebóides e venuladas na rocha.

Os cristais de calcita são anedrais, às vezes alongados e seus contornos muitas vezes são denteados.

O material silicático é representado por uma massa afanítica de cor acastanhada composta por vidro desvitrificado, zeolita e lepidocrocita. Contém raros fenocristäis de titanaugita ou então esqueletos de olivina.

$O$ fácies $b$ diferencia-se do fácies anterior só por conter grande quantidade de fenocristais de titanaugita e de flogopita, as quais chegam a atingir até $2 \mathrm{~cm}$. A olivina, quando presente, ocorre em pseudomorfos limonitizados.

Em alguns afloramentos, este fácies apresenta uma nítida estratificação plano-aparalela atestando sua origem tufácea. Trata-se de tufos de cristais ricos em uma emulsão carbonatítica. Úma característica comum aos fácies descritos é a presença de uma fina franja de reação entre a porção carbonática e a silicática. Trata-se de um mineral finamente cristalizado e de aspecto fibroso provavelmente de natureza zeolítica. 
O fácies esferoidal (c) consiste em uma rocha de cor amarronzada, pintalgada por glóbulos brancos de carbonato. Têm muitas vezes aspecto aglomerático, apresentando fragmentos bem arredondados de diâmetro médio entre 2 e $5 \mathrm{~cm}$. Estes podem estar envoltos por um fino material de cor acastanhada ou por carbonato. Às vezes, a rocha mostra uma estrutura venulada devido à coalescência de esferas calcíticas. Estas vênulas, por sua vez, delimitam fragmentos lávicos. Neste caso parecem tratar-se de brechas formadas por fluxo.

As esferas têm diâmetro médio pouco menor que 1 mm e a maioria delas se tangencia ou está muito próxima. Em alguns casos, pode-se observar o início de coalescência das esferas, evoluindo para formas típicas dos fácies antes descritos. São preenchidas principalmente por calcita que ocorrem em cristais anedrais ou roboédricos. Em raros casos há pequenas porçð̃es reliquiares de zeolitas pseudomorfizadas por calcita.

Essas esferas diferenciam-se das amígdalas de outras lavas, pelos seguintes aspectos:

a. Forma esférica surpreendentemente perfeita e constante.

$b$. Na superfície das esferas há uma capa muito fina de material normalmente isotrópico, determinando-lhes um contorno regular.

c. Presença de cristais prismáticos de clinopiroxênios da matriz, tangenciando as esferas.

d. Quantidade de cristais de calcita, em cada esfera, normalmente superior a dez indivíduos cristalinos enquanto nas amígdalas há só dois ou três indivíduos de dimensőes maiores.

$e$. Grande quantidade de esferas (normalmente entre $60 \%$ e $65 \%$ da rocha).

Algumas vezes, estas esferas podem exibir um achatamento acompanhado de uma orientação que lembra linhas fluidais. Se este aspecto for realmente resultado de fluxo, como realmente parece ser, é curioso que as esferas não tenham coalescido.

A fração silicática desta rocha possui grande quantidade de finas ripas de clinopiroxênio (substituídas por carbonato) e pseudomorfos de fenocristais de olivina (hidróxidos de ferro).

A porcentagem da fração carbonática, em toda a seqüência, varia entre aproximadamente $30 \%$ e $65 \%$, sendo os valores mais altos observados no fácies esferoidal.

\section{4 - FONÓLITOS E TRAQUITOS Afora dois con-} dutos fonolíticos, estas rochas são abundantemente encontradas como seixos na Formação Verdinho. Em face disto, é provável que tais rochas tenham constituído grande parte das porçôes apicais dos antigos edifícios vulcânicos que foram desmantelados pela erosão. Representam os termos mais diferenciados do vulcanismo alcalino da área.

Microscopicamente, apresentam textura porfirítica, microporfirítica ou glomeroporfirítica, com matriz traquítica ou granular hipidiomórfica. Oș fenocristais comumente são de aegirina-augita e ainda de sanidina, biotita ou hornblenda basáltica. A matriz é constituída principalmente por prismas curtos ou alongados de sanidina e, em alguns casos, de ortoclásio, que podem estar orientados ou não.
Nos fonólitos estudados, o feldspatóide presente é a analcima e não a nefelina. Caracteristicamente, possui inclusões de finos cristais de clinopiroxênio concentricamente arranjados.

\section{B - CARACTERIZAÇÃO DO MAGMATISMO}

A discussão petrogenética que se segue fundamentase em aspectos mineralógicos e estruturais dos vários tipos petrográficos encontrados na área. Assim, trata-se de uma primeira aproximação ao problema já que o conhecimento de toda a província poderia apresentar tipos petrográficos e aspectos até aqui desconhecidos e também porque o estudo petroquímico da província ainda se encontra em andamento.

O magma que originou as diversas rochas da província é do tipo nefelinítico, pelo que se pode deduzir das seguintes feiçoes petrográficas:

1. Subsaturação em sílica evidenciada pela abundância de analcima. Esta subsaturação deve ser menor que a apresentada por magmas nefeliníticos típicos, uma vez que a analcima é mais rica em $\mathrm{SiO}_{2}$ que a nefelina.

2. A presença de perovskita e conseqüente ausência de feldspatos. A presença de perovskita é diagnosticada da série de magmas nefeliniticos. De acordo com Carmichael et. al. (1974), a reação

$$
\mathrm{CaTiO}_{3}+\mathrm{SiO}_{2}=\mathrm{CaTiSiO}_{5}
$$$$
\text { Perovskita }+ \text { Vidro }=\text { Esfeno }
$$

delimita os campos de atividade de $\mathrm{SiO}_{2}$ dos magmas nefelíticos e basálticos alcalinos. A ausência de esfeno, bem como de plagioclásio nas rochas analcimíticas, comprova de per si a forte insaturação do magma original.

3. Fases máficas representadas por olivina do tipo crisolita e por clinopiroxênio rico em Ti e $\mathrm{Ca}$. O clinopiroxênio rico em Ti e Ca é típico dessè tipo de lavas (Carmichael et. al., 1974; e Almeida, 1958 e 1961). A presença de crisolita é comum.

4. Abundância de voláteis, representada pela grande quantidade de zeólitas e carbonato. Esta abundância de voláteis (incluindo $\mathrm{CO}_{2}$ ) é típica nos magmas nefeliníticos (Bailey, 1974), a qual se manifesta também pelo caráter explosivo do vulcanismo, como é o caso da província em estudo.

Pode-se, pois, concluir que o magma do vulcanismo de Santo Antônio da Barra é do tipo nefelinítico, provavelmente um pouco mais enriquecido em sílica que os magmas nefeliníticos típicos devido à presença de analcima, em vez de nefelina.

Na província, os tipos petrográficos encontrados podem ser encarados como partes de uma série de diferenciação magmática, que poderia ser esquematizada como se segue:

1 - XENÓLITOS DE DUNITOS E WHERLITOS Estes representam o fracionamento maǵmático inicial com cumulados de olivina e clinopiroxênio intercumulus em condições de câmaras profundas. No SW de Goiás seriam geologicamente representados pelos complexos do tipo Iporá (Danni, 1974).

2 - ANALCIMITOS Entre os analcimitos são distintos os olivina analcimitos por possuírem quantidades 
apreciáveis deste mineral como fenocristais. Representam frações magmáticas primitivas capazes de fracionar a olivina. Evoluem para os titanaugita analcimitos, caracteristicamente desprovido de olivina. Estes, dada a ampla abundância na província, constituem provavelmente os termos lávicos mais próximos do magma parental.

3 - ANALCIMA FONÓlitos Apesar de ocorrência restrita, tais rochas devem representar residuos diferenciados do magma tipo "nefelinítico" (isto é, no caso analcimítico). Esta inferência é apoiada pela presença de analcima e pela íntima associação geológica com as rochas anteriores. É importante frisar que a analcima traz implicaçðes diretas quanto à insaturação em sílica do magma, a quantidade de $\mathrm{H}_{2} \mathrm{O}$ e as condiçðes muito específicas de sua formação (Gaspar e Danni, 1979).'

A sequêencia de diferenciação mais provável é a seguinte:

Vulcânicas

Ólivina analcimito-Analcimito-Analcima fonólito \pm Traquilito.

Hipoabissais

Melamonchiquito-Fourchito-Analcima fonólito

4 - ROCHAS CARBONATÍTICAS As rochas carbonatíticas registram a fase final do magmatismo em razão de recobrirem as lavas e brechas bem como por ocuparem a parte central do principal conduto vulcânico identificado na área (Fig. 4).

O questionamento, que nasceu com a descoberta dessas lavas, repousou no fato de serem ou não representantes extrusivas de magmas carbonatíticas. Os fatos que as aproximam dos carbonatitos são os seguintes:

1. Teores em carbonato que variam de $30 \%$ a $65 \%$ : segundo Brogger (1921, in Heinrich, 1966), tais rochas são classificadas genericamente como silicocarbonatitos.

2. Associação com nefelinitos (Le Bas, 1977).

3. O fato de representarem as fases finais do magmatismo.

A existência de efusð̃es de lavas carbonatíticas é rara, tendo sido descritas pela primeira vez por Dawson (1962), no vulcão Oldoinyo Lengai, para lavas compostas por carbonatos de sódio. Posteriormente, foram descritos lavas e tufos em Uganda (Nixon e Hornung, 1973), na ex-Tanganica (Dawson, $1964 a$ e 1964b) e na Tanzânia (Hay, 1978). Esta última ocorrência é composta por tufos que mostram muita semelhança com as rochas carbonatíticas encontradas na área, principalmente com a fácies esferoidal. As esferas carbonáticas são consideradas por Hay (op. cit.) como glóbulos de carbonatito. Uma das características seguras de identificação de rochas carbonatíticas é pela dosagem de alguns elementos menores, tais como, $\mathrm{Ba}, \mathrm{Sr}$ e Terras Raras (Gold, 1966; e Loubet et al., 1972). No entanto, as primeiras dosagens para $\mathrm{Ba}$ e $\mathrm{Sr}$ realizadas em rochas da província não são coerentes com uma natureza carbonatítica, como pode ser observado na Tab. 1. Por outro lado, deduz-se do trabalho de Hay (1978) que as transformaçðes secundárias e intempéricas sofridas por esses tipos de rochas envolvem amplos processos de substituição e recristalização de carbonatos, os quais
Tabela 1 - Dosagens em ppm para a lava carbonatítica

\begin{tabular}{ccc}
\hline & $\begin{array}{c}\text { Lava carbonatítica } \\
\text { (rocha total) }\end{array}$ & $\begin{array}{c}\text { Fração carbonática da } \\
\text { rocha anterior }\end{array}$ \\
\hline $\mathrm{Ba}$ & 900 & 50 \\
$\mathrm{Sr}$ & 550 & 450 \\
$\mathrm{La}$ & $<200$ & $<200$
\end{tabular}

podem perder assim suas características químicas primárias.

Um aspecto muito interessante dessas rochas é a presença da fácies esferoidal, a qual é formada por inúmeras esferas quase perfeitas, compostas por cristais de carbonatos, mergulhadas em uma matriz vítrea, zeolitizada e carbonatizada.

Quanto à interpretação genética dessas lavas, a primeira idéia que surge é que as esferas representam uma fase carbonática descontínua, imiscível na fase silicática. A estrutura, como hoje observada, representaria a preservação de um determinado momento na separação de líquidos imiscíveis de composiçóes silicática e carbonatítica, fossilizando então um estágio inicial de imiscibilidade dos líquidos, anterior ao que evoluiria à coalescência da fase carbonática.

Recentemente, Keller (1981) demonstrou a existência de lapilis formados pela ejeção de gotas carbonatíticas representativas de fusões de líquidos cálcio-carbonatíticos no Complexo alcalino de Kaisertuhl (Alemanha Ocidental).

A imiscibilidade entre líquidos carbonatíticos e silicáticos foi demonstrada experimentalmente por Koster van Gross e Wyllie (1973), no sistema $\mathrm{NaAlSi}_{3}$ $\left.\mathrm{O}_{8}-\mathrm{CaAl}_{2} \mathrm{Si}_{2} \mathrm{O}_{8}-\mathrm{Na}_{2} \mathrm{CO}_{3}\right\lrcorner \mathrm{H}_{2} \mathrm{O}$; para temperaturas acima de $750^{\circ} \mathrm{C}$. Observaram também que, acima desta temperatura, coexiste uma fase fluida aquosa enriquecida em silicato de sódio e $\mathrm{CO}_{2}$. A fase silicática observada experimentalmente caracteriza-se por ser "peralcalina e fortemente subsaturada em sílica".

-Na rocha em questão, a fase fluida poderia ser a responsável pela zeolitização e carbonatização das fases silicáticas, que, por sua vez, possuem aqui um caráter muito semelhante ao observado experimentalmente.

No entanto, a presença de pseudomorfos de minerais substituídos por carbonatos, dentrò desses esferóides, leva a dúvida de que a fase carbonática tenha sido líquida, principalmente porque pequenas porções relíquias desses minerais apresentam características ópticas semelhantes às zeólitas. Neste caso, a cristalização do carbonato teria sido posterior à zeólita e certamente a partir de uma fase fluida e gasosa. A presença de fácies piroclásticas evidencia uma abundância de gases, mas não implica que a fase carbonática tenha sido exclusivamente gasosa. Principalmente porque, conforme já foi citado anteriormente (Hay, 1978), a história pós-magmática dessas rochas é complexa e obscurece muitas das feiçð̃es primárias.

Tendo sido gasosa ou líquida a fração carbonática, a presença dessas esferas é um aspecto interessante em termos das condições que permitiram sua formação. É imperioso que tenha havido estabilidade do magma desde. o início da separação da fase carbonática, desde pelo menos o início da cristalização dos fenocristais As porçoes de lavas que se submeteram à maior mobilidade 
propiciaram a coalescência das esferas carbonáticas, que assim perdem sua individualidade dando origem a bolsőes, vênulas e massas irregulares, intimamente associadas às frações siliçáticas. Tanto o momento de coalescência quanto a forma dependem em certo grau da tensão superficial da fase descontínua (McBirney e Murase, 1970).

Ao que tudo indica, as etapas de forte descompressão que deram origem às fases de magmatismo explosivo da província processaram-se em condiçốes sub- vulcâncias e devem ter sido geradas pelo aumento da tensão interna num sistema gás-líquido carbonatítico e liquido nefelinítico durante o processo de diferenciação. Nessas condições, a separação das fases voláteis e líquidas deve ter atingido o clímax possibilitando então a emissão tardia de tufo-lavas sílico-carbonáticos. Localmente, tais produtos vulcânicos estão preservados no interior de uma antiga chaminé vulcânica numa situação parecida com a que ocorre em Napak, na África (King, 1965).

\section{BIBLIOGRAFIA}

AlMEIDA, F, F. M. de - 1958 - "Geologia e Petrologia do Arquipélago de Fernando de Noronha" Monogr. XIII, DNPM-DGM.

ALMEIDA, F. F. M. de - 1961 - "Geologia e Petrologia da Ilha da Trindade". Monogr. XVIII, DNPM-DGM.

BAILEY, D. K. - 1974 - - "Nephelinites and ijolites". In "The Alkaline Rocks". H. Sorensen, Edit. John Wiley \& Sons.

BARBOSA, O., BRAUN, O. P. G., DYER, R. C. e CUNHA, C. A. B. R. 1970 - "Geologia da Regiåo do Triângulo Mineiro". Div. Fom. Prọd. Min,, DNPM, Bol. 136, Rio de Janeiro.

BEZ, L. e GUIMARÃES, D. - 1971 - "Distrito Vulcânico de Rio Verde Anais", XXV Cong. Bras. Geal., SBG, pp. 121-128.

CARMICHAEL, I. S. E., TURNER, F. J. e VERHOOGEN, J. -m 1974 - "Igneous Petrology". McGraw-Hill Book Company.

DANNI, J. C. M. - 1974 m "Géologie des Complexes Ultrabasiques Alcalines de la Région d'Iporá, Goiás". Tese à Université de Paris Sud.

DAWSON, J. B. - 1962 - "Sodium carbonate lavas from Oldoinyo Lengai, Tanganyika". Nature 195, 1075-1076.

DAWSON, J. B. - 1974a- "Carbonatitic volcanic ashes in Northern Tanganyika". Bull. Vulcan. 27, 81-92.

DAWSON, J. B. - $1964 b$ - "Carbonate tuff cones in Northern Tanganyika". Geol. Mag. 101, ก: 2, 129-137

FISCHER, R. V. - 1966 - "Rocks composed of vulcanic fragments and their classification". Earth-Sci. Rev., 1, 287-298

GASPAR, J. C. - 1977 - "Contribuiçzo ao Estudo do Magmatismo Alcalino de Santo Antônio da Barra, GO". Tese à Universidade de Brasilia.

GASPAR, J. C. e DANNI, J. C. M. - 1979 -_ "Analcima nas rochas vulcânicas de Santo Antônio da Barra, Goiás, e suas possiveis implicaçőes petrogenéticas. Bol. Min. 6, 41-49.

GOLD, D. P. - 1966 - "The Average and Typical Chemical Composition of Carbonatites". Min Soc. Ind. IMA volume 83-91,

HASUI, Y, - 1968 - "A Formação Uberaba", Anais XXII Cong. Bras. Geol., SBG, 167-179.

HASUI, Y., ALMEIDA, F. F. M. de, HARALYI, N. L. E., DAVINO, A. e SVISERO, D. P. - 1936 - "Contexto Tectônico dos Carbonatitos do Oeste de Minas Gerais e sul de Goiás". (Res) Inter. Symp. Carbonatites, Poços de Caldas.

HASUI, Y., DYER, R. C. e IWANUCH, W. - 1971 - "Geocronologia das Rochas Alcalinas de Santo António da Barra, GO". Anais XXV Cong, Bras. Geol., SBG, 253-258.
HAY, R. L. - 1978 - "Melilitite-Carbonatite Tuffs in the Laetolil Beds of Tanzania". Contrib. Mineral. Petrol, 67, 357-367.

HEINRICH, E. W. - 1966 - "The Geology of Carbonatites". Rand McNally, Chicago.

JOHANNSEN, A. - 1938 - A Descriptive Petrography of the Igneous Rocks", v. IV, Univ. of Chicago Press. Chicago.

KELLER, J. - 1981 - "Carbonatitic volcanism in the kaisertuhl alkaline complex: evidence for highly fluid carbonatitic melts at the Earth's surface". Journ. volc. and geothermal research 9, 423-431.

KINK, B. C. - 1965 - "Petrogenesis of the alkaline igneous suites of Eastern Uganda". Journ. Petrol., 6, part. 1, 67-100.

KOSTER VAN GROSS, A. F, e WYLLIE, P, J. - 1973 - "Liquid immiscibility in the join $\mathrm{NaAlSi}_{3} \mathrm{O}_{8} \cdot \mathrm{CaAl}_{2} \mathrm{Si}_{2} \mathrm{O}_{8}-\mathrm{Na}_{2} \mathrm{CO}_{3}+\mathrm{H}_{2} \mathrm{O}^{\prime \prime}$. Am. Jourm. Scie. 273, 465.487.

LADEIRA, E. A., BRAUN, O. P. G., CARDOSO, R. N. e HASUI, Y. - 1971 "O crétáceo em Minas Gerais". Anais XXV Cong. Bras. Geol, SBG, 15-31.

LADEIRA, E. A. e BRITO, O. E. A. de - 1968 - "Contribuicăo à Geologia do Planalto da Mata da Corda". Anais XXII Cong. Bras, Geol., SBG, 181-199.

LE BAS, M. J. - 1977 - "Carbonatite-Nephelinite Volcanism". John Wiley \& Sons.

LOUBERT, M. BERNAT, M., JÁVOY, M. e ALLEGRE, C. J. - 1972 - "Rare Earth contents in carbonatites". Earth Plan. Sci. Letters., 14 (2), 226-232.

McBIRNEY, A. R. e MURASE, T. - 1970 - "Factores Governing the Formation of Pyroclastic Rocks". Bull. Vulc. Tomo 34, Fac. 2, 372-384.

NIXON, P. H. e HORNUNG, G. - 1973 - "The Carbonatites Lavas and Tuff near Fort Portal, Western Uganda". Overseas Geol. Min. Res, 41, 168-179.

PENA, G. S. - 1974 - "Geologia da Área do Projeto Goiania II, Sudoeste de Goias". Anais XXVIII Cong. Bras. Geol., SBG, v. 4, 37-50.

SADOWSKI, G. - 1976 - "Ativaçăo de Plataforma na América do Sul e Zonas de Fratura do Atlântico Sul”. Res. Trab. 29: Congr. Bras. Geol., SBG, 183-184, Belo Horizonte.

STRECKEISEN, A. - 1978 - "Classification and Nomenclature of Volcanic Rocks, Lamprophyres, Carbonatites and Melilitic Rocks". N. Jb. Miner. Abh. 134 (1), 1-14 